University of Nebraska - Lincoln

DigitalCommons@University of Nebraska - Lincoln

Architecture Program: Faculty Scholarly and

Creative Activity

Architecture Program

2005

\title{
How Does Immigration Impact on the Quality of Life in a Small Town?
}

James J. Potter

University of Nebraska-Lincoln, jpotter2@unl.edu

Rodrigo Cantarero

University of Nebraska-Lincoln, rcantarero1@unl.edu

X. Winston Yan

University of Nebraska-Lincoln

Steven Larrick

University of Nebraska-Lincoln

Heather Keele

University of Nebraska-Lincoln

See next page for additional authors

Follow this and additional works at: https://digitalcommons.unl.edu/arch_facultyschol

Part of the Architecture Commons

Potter, James J.; Cantarero, Rodrigo; Yan, X. Winston; Larrick, Steven; Keele, Heather; and Ramirez, Blanca E., "How Does Immigration Impact on the Quality of Life in a Small Town?" (2005). Architecture Program: Faculty Scholarly and Creative Activity. 33.

https://digitalcommons.unl.edu/arch_facultyschol/33

This Article is brought to you for free and open access by the Architecture Program at DigitalCommons@University of Nebraska - Lincoln. It has been accepted for inclusion in Architecture Program: Faculty Scholarly and Creative Activity by an authorized administrator of DigitalCommons@University of Nebraska - Lincoln. 


\section{Authors}

James J. Potter, Rodrigo Cantarero, X. Winston Yan, Steven Larrick, Heather Keele, and Blanca E. Ramirez 


\title{
Chapter 8
}

\section{How Does Immigration Impact on the Quality of Life in a Small Town?}

\author{
James J. Potter, Rodrigo Cantarero, X. Winston Yan, \\ Steven Larrick, Heather Keele and Blanca E. Ramirez
}

\section{Introduction}

Throughout the world, people are migrating from rural areas to cities to find jobs and to seek a better life. As a result, many cities and regions are experiencing population influx. Many small midwestern communities have been experiencing these rapid demographic changes. 'In the 1990s, Nebraska rural counties continue(d) to experience out-migration of the young, working-age population, with remaining residents tending to be older. However, the 1980 s and current outmigrants are being replaced by in-migrants' (Austin, 1996). Lured by jobs in the food processing industry (mainly meatpacking), many towns and cities have been experiencing a significant increase of new residents, mostly Latino, over the past 15 years. These changes tend to bring renewed economic vigor but they also present a complex array of physical, social, psychological, and cultural challenges. 'As in the case of Nebraska, an increase in the meatpacking industry and American minority and foreign immigration has definitely impacted rural communities, in terms of housing and quality of life issues' (Potter et al., 1996); coordination of human services (IANR, 1995); Hispanic migrant laborer homelessness (Gaber and Cantarero, 1997); community development (Gouveia and Stull, 1997); and language issues (Gouveia and Rousseau, 1995), (Ramirez, 1998) The resulting rapid and often unmanaged growth puts a strain on communities as well as on individual households. The fiscal viability of communities may be threatened, degradation of the environment can be exacerbated, and, in general, the quality of life may be diminished for both long-time residents and newly arrived residents. At the family level, individuals may suffer the stress of overcrowding, marital discord, child abuse, teenage rebellion, crime and a general loss of community identity.

This chapter reports a study that investigated issues pertinent to the impact of population influx due to migration on small cities, towns and communities. There are two primary reasons that led the researchers of this project to believe that the impact on small cities and towns was quite different from that on large cities. First, unlike large cities that often have greater resources, small cities and 
communities have limited resources to cope with pressures of population influx on their housing, infrastructure and municipal services. Big cities can readily absorb large numbers of immigrants due to their economies of scale, available housing of greater variety and social and cultural networks. Secondly, while the social and cultural environments of large cities are often diverse, small cities tend to be more socially, culturally and ethnically homogeneous. When the new comers are from a different cultural background, their arrival inevitably impacts the social and cultural homogeneity of the community.

This is precisely what has been happening in the city of Crete, Nebraska. Crete is located in Saline County and is approximately a 30-minute drive from Lincoln, which is Nebraska's Capitol City. Similar to other Nebraska counties, Saline County's demographic change can mainly be attributed to the growth in one or two communities. According to the US Census, Saline County had a total population of 12,715 in 1990 and by the 2000 Census it had experienced an increase to 13,843 . This is an additional 1,128 residents (an $8.9 \%$ change). During the same time period, the Hispanic/Latino population grew by 911 persons in the County (a $9.85 \%$ change). Saline County's population increase is primarily due to the increase in Crete's population. Crete has been experiencing growth in population and change in the racial/ethnic makeup of its residents. According to the US Census, Crete's total population in 1990 was 4,841 and increased to 6,028 by the year 2000 . This demonstrates a $24.5 \%$ increase in the population by 1,187 persons.

Crete was founded in 1870 , partially due to the creation of Crete Mills, a Lauhoff Grain Company that produces food grain products. In 1910 Douglas Manufacturing opened (manufactures voting equipment), in 1965 Allen Products Company was established (now Friskies Pet Care Company, manufactures all meat dog food), in 1975 Farmland Foods was established (processes pork for the national and international market). In 1984 the first immigrants began arriving in Crete, Farmland Foods employed merely 12-15 Vietnamese workers to begin. In the later 1980s more Vietnamese families came to Crete for resettlement, and in the early 1990s Hispanics began to move to Crete from other meatpacking communities. In the late 1990s Bosnians moved to Crete through resettlement programs. Between December of 1999 and December of 2000, there was a $25 \%$ jump in the production work force in Crete, in part due to Farmland's ongoing expansion and high starting pay. Currently only half of Farmland's work force lives in Crete, or nearby Wilber, the other half lives in Lincoln. Crete's major industries are Farmland, Friskies, and Crete Mills. The company with the greatest number of immigrants is Farmland. Currently, Farmland has approximately 1,400 total employees, including production and adminfstration. Because of the ethnically diverse employment population at Farmland, thirteen (13) languages are spoken at the plant. The different racial/ethnic groups employed by Farmland are Hispanic (250-300); Vietnamese (200-250); Bosnian (50-60); Chinese; Korean; Laotian; Croatian; Russian; Iraqi; etc. ${ }^{1}$

Although, the migration of persons from various ethnicities may have presented challenges to Crete leaders and community residents, this has also given

\footnotetext{
${ }^{1}$ Information provided by Farmland representative.
} 
opportunities to engage in more cultural diversity dialogues and events. According to Farmland officials, the company has a Communications Committee designated to create programs celebrating diversity. For example, in 1999, a soccer team including Hispanic and Vietnamese players received sponsorship from the company. Furthermore, the Hispanic community is becoming more established in Crete and they are opening up restaurants and grocery stores.

The demographic changes occurring in Crete are brought about by a number of factors: 1) The availability of employment opportunities at Farmland, a pork processing plant; 2 ) the resettlement of refugees through organizations located in Lincoln, and; 3) word-of-mouth invitations by current Crete residents to their friends, families and acquaintances. The wave of newly arrived residents adds new life to the city and to its community, especially when many of them came from a culture that is distinctively different from that of the current residents. On the other hand, a flood of new immigrants poses a variety of unexpected challenges to the city.

The most immediately experienced impact of the latest population influx was on the city's housing, especially its affordable housing. The new arrivals needed affordable housing to buy and to rent. The municipal services such as schools, public transportation systems and hospitals were also in great need for expansion in order to accommodate the population growth.

Impact on its previously rather homogenous social and cultural environment is also quite obvious. Like other small cities in many parts of the US, residents in Crete in general had been quite homogenous both culturally and ethnically until the recent population influx. The new population influx of people with distinctively different cultural and ethnic background exerted an impact on the existing cultural homogeneity, and triggered a process of transformation from cultural homogeneity to heterogeneity.

\section{The Study Methods}

In the fall of 2000, Steve Larrick, Community Development Coordinator for UNL's College of Architecture, received a request from the City of Crete to study housing and quality of life issues. The Quality of Life team met with representatives from the City of Crete, Farmland and Doane College. During the meeting, the research team described the 'Housing and the Quality of Life in Schuyler, Nebraska' study (Potter et al., 1996) which would be used as a model for a study in Crete. The representatives were in support of the research model. From 1995 through 1996 a group of architectural and planning researchers at the University of Nebraska-Lincoln conducted a study to learn about the impact of the population influx on the physical environment and quality of lives of Schuyler. This study had two main objectives. First, it wanted to find out residents' perceptions of the city and its change in the physical, social and cultural environment as a result of the population influx. Secondly, it intended to identify issues that had direct or indirect implications for city housing and planning. The 
Crete study would help explore the impacts of a Nebraska small town environment on newly arrived residents (more than 15 years) and long-time residents (less than five years).

\section{The Methodology Utilized in this Study can be Summarized in Four Phases}

PHASE I: Establishing Trust The main goal of this phase was to build trust with city officials in order to gain their input on the housing and quality of life issues. In addition, this stage also became important because researchers familiarized themselves with general community resources as well as those serving newly arrived residents. An initial meeting of December 13, 2000 between UN-L researchers and Crete officials marked the first of several meetings where the information provided became the vehicle for coordinating focus groups, designing and testing the questionnaire, locating the target population, and hiring Doane college students as interviewers.

PHASE II: Identifying Issue The primary goal of this phase was to gather information from meetings, conduct a literature search, collect newspaper articles, utilize US Census data, and gather feedback from focus groups. The literature search (i.e., newspaper and journal articles) helped in providing a picture of the historical forces that have shaped the current condition in Crete, NE. Furthermore, the Focus Groups (at least one for each target group) became a means of better understanding community residents' perceptions of the housing and quality of life issues.

PHASE III: Surveying for Resident Perceptions In February, the Quality of Life Study Team began developing the survey instrument for Crete, while utilizing the Schuyler questionnaire as a baseline. In developing the questionnaire, the following were utilized to come up with a final draft: two focus groups with newly arrived residents, one focus group with long-time residents. Some of the issues identified by newly arrived residents were: integration, communication, understanding federal and local laws/rules/regulations, the impact of being undocumented on obtaining a driver's license/health insurance/auto insurance, lack of transportation, and need for diversified shopping areas. On February 27, 2001, researchers met with Crete Collaborating team to discuss the survey draft. Crete City officials gave feedback, and the final changes were made. The questionnaire was tested in English and Spanish and made available to Doane College students to conduct in the community. Doane students were trained as interviewers and other interviewers were utilized from another research project Dr. Rodrigo Cantarero was running.

The goal of the household studies was to provide an assessment of the housing conditions (as perceived by both the recently arrived residents and the long-time residents), the stress associated with the changes in the community and how their well being has been affected as a result of those changes. Participants of the LongTime Resident Interviews were individuals who have lived in Crete prior to January 1986. Newly arrived residents were defined as any person who has lived 
in Crete since January 1996. No Crete residents who moved to Crete after January 1986 and before January 1996 would be interviewed. Besides meeting the resident requirement, potential participants had to meet the age requirement of currently being 20 years of age or older.

PHASE IV: Analyzing the Survey Results The data was analyzed using SPSS. The two groups were compared with regard to their responses to each survey question.

\section{Survey Results and Discussion}

When considering the results of the survey there are many ways to present the information. To facilitate understanding, the results have been organized into two sections. The first section addresses issues in which the perceptions of long-time and newly arrived residents are similar. The second section discusses those issues for which perceptions of long-time and newly arrived residents are significantly different.

\section{Similarities in Perception}

The following are areas where there were not significant differences between responses of long-time and newly arrived residents $(\mathrm{p}<.05)$.

Satisfaction of the Residents with their lives in Crete Do residents feel satisfied with their lives in Crete? Long-time and newly arrived residents are generally satisfied with housing issues within the context of their neighborhood and the city of Crete. Both the long-time and newly arrived residents agreed that they had no problem with rodents or bugs in their residences, the plumbing condition was generally rated good, as well as the condition of appliances. Long-time and newly arrived residents are satisfied with many other aspects of the residential neighborhood. 


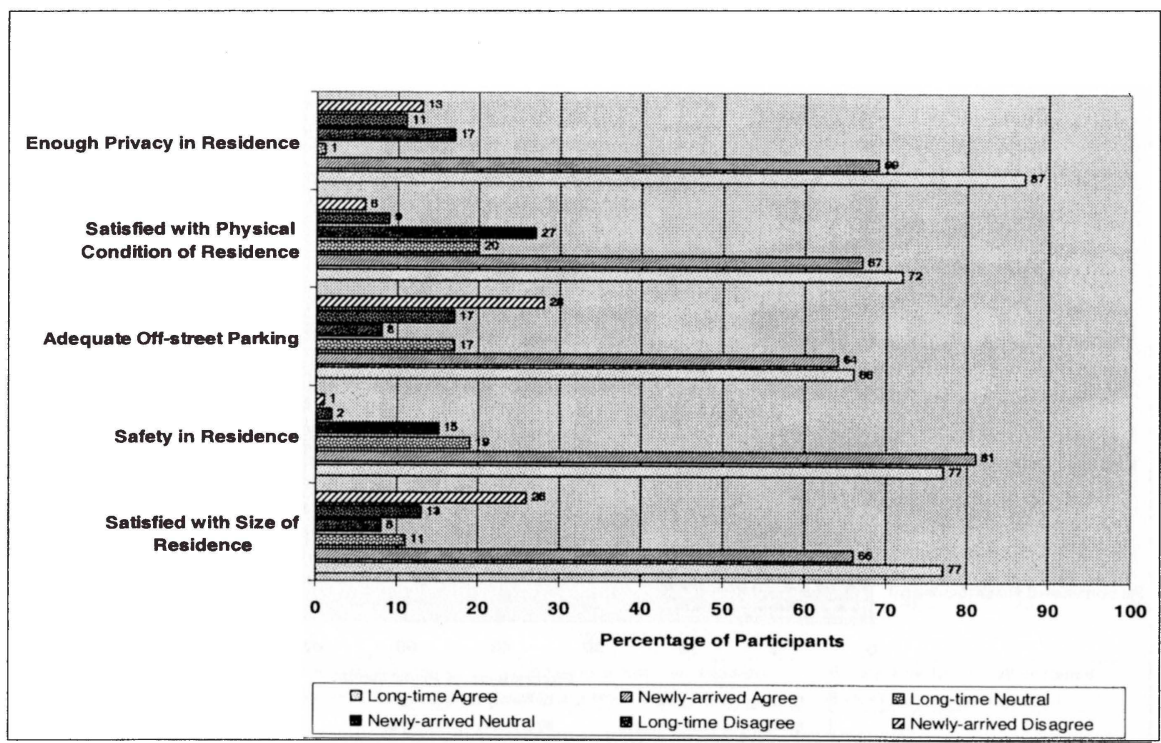

\section{Figure 8.1 Perception similarities: Satisfaction with life in Crete}

They agree that they have adequate off street parking, they are satisfied with the level of safety from being a victim of a crime while in their residence, they are satisfied with the overall physical condition of their residence, they are generally satisfied with the size of their residence, and they feel that they have sufficient privacy from neighbors.

Pressure on Public Municipal Services Do residents perceive there is a pressure on public municipal services? Long-time and newly arrived residents are satisfied with many public service issues within the city of Crete, as is evident in Figure 8.2. 


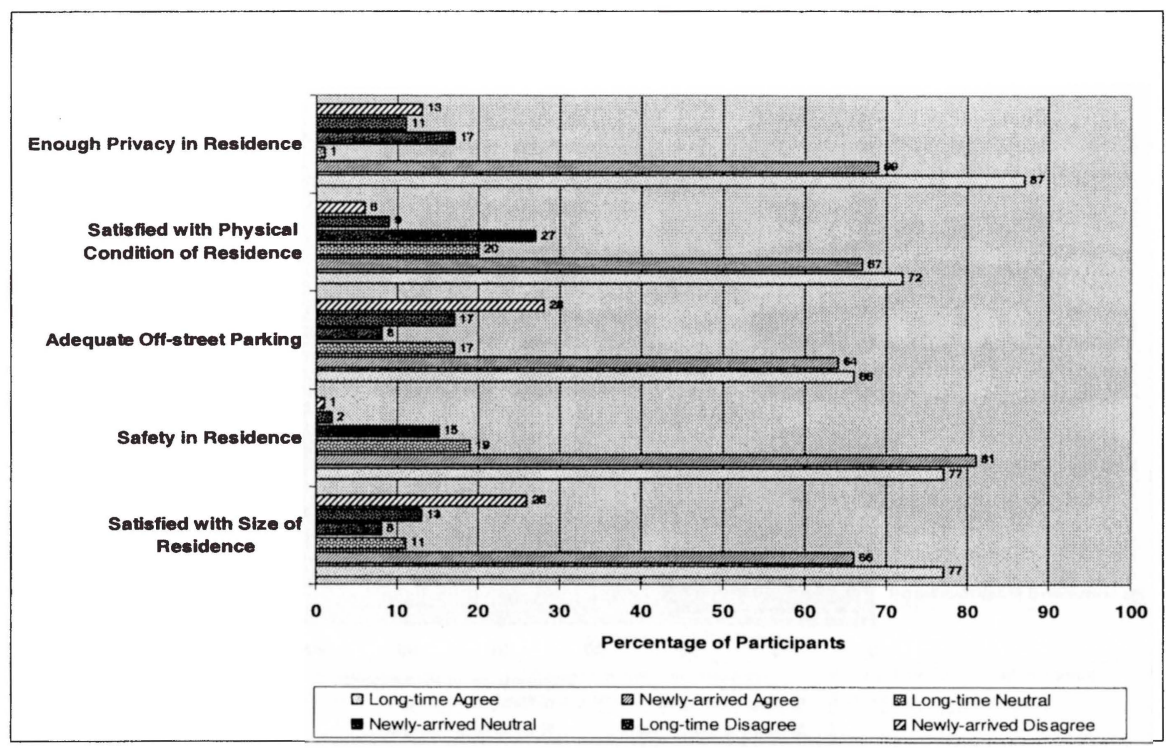

Figure 8.2 Perception similarities: Pressure on public municipal services

Both groups of residents are satisfied with the level of street maintenance and garbage collection in the neighborhood, and they rated the overall visual attractiveness of the neighborhood as satisfactory. Generally both groups rated the overall quality of air in the neighborhood as satisfactory, as well as the adequacy of public services. Long-time and newly arrived residents agree in their satisfaction with many aspects of service in the city of Crete. Both groups of residents are satisfied with the level of police protection and access to recreation services.

Stress of New Arrivals How did the new arrivals evaluate their new lives in Crete and what sources of stress did they experience most? As shown in Figure 8.3, long-time and newly arrived residents agree on many stress related concerns. 


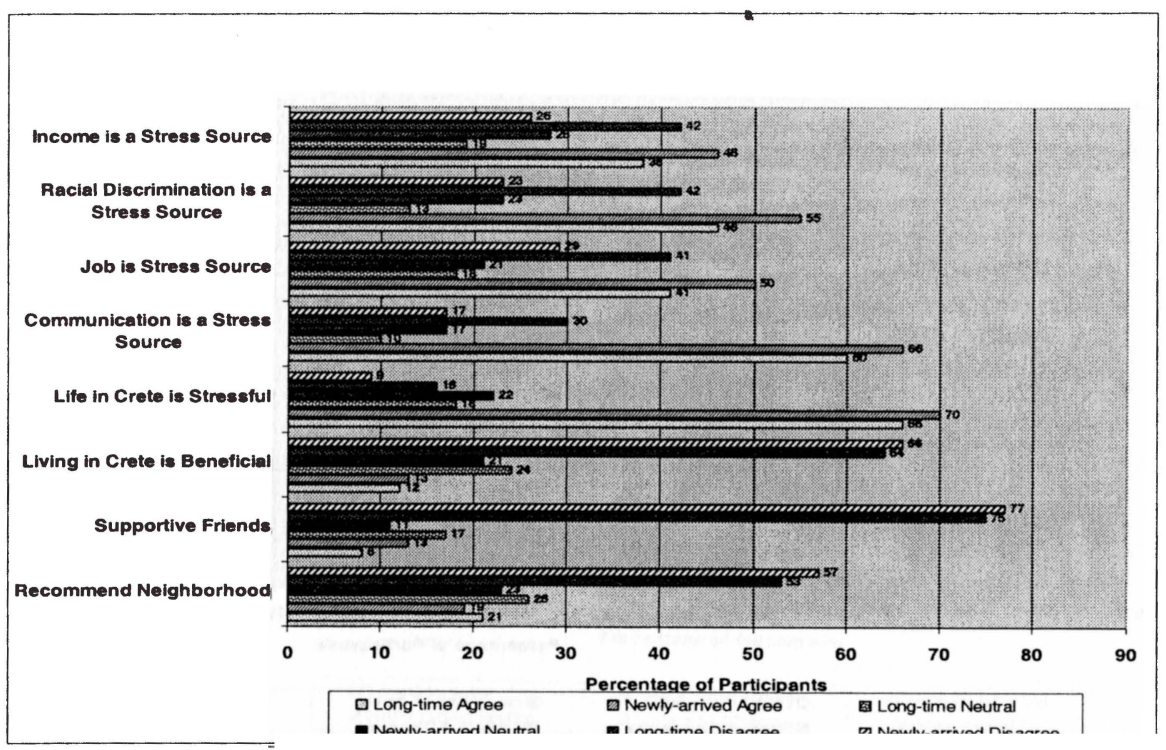

Figure 8.3 Perception similarities: Stress related concerns

Both groups agree that they can rely on friends for support in times of need, that living in Crete is beneficial for their family, and that they would recommend their immediate neighborhood to a friend. Both groups disagree with the statements life in Crete is very stressful and an inability to communicate with others is stressful for themselves. The subject of income as a source of stress garnered mixed perceptions among the groups, but generally neither group feels that income is a source of stress for them, with $45.7 \%$ of long-time residents and $38.5 \%$ of newly arrived residents disagreeing that income is a source of stress. In opposition to these findings, $42.3 \%$ of the newly arrived residents agreed that their level of income was a source of stress, while only $26.1 \%$ of long-time residents agreed their income was a source of stress. In general half of all residents disagree that racial discrimination is a source of stress. Both groups are split in their agreement concerning how their job (or lack of job) is a source of stress.

The Change in Neighborhoods: From Homogeneity to Heterogeneity Long-time and newly arrived residents agree on many aspects of the current housing condition in the city of Crete. 


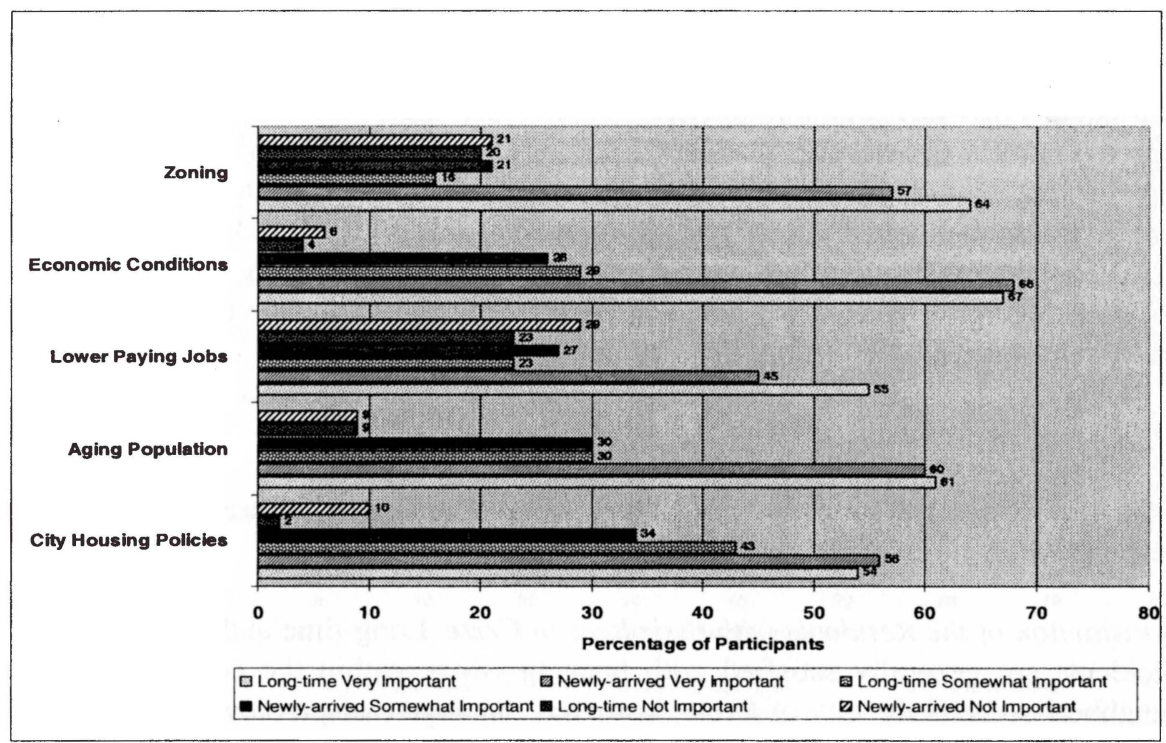

\section{Figure 8.4 Perception similarities: Importance of factor in current housing condition}

Both groups agree that the aging of resident population and the economic conditions, including lower paid jobs, are important factors contributing to the current housing conditions. They also agree that the city housing policies and zoning conditions are important factors contributing to the current housing conditions. Long-time and newly arrived residents agree on most social/cultural issues in the city of Crete. Both groups of residents are satisfied with the 'sense of community' in Crete, and with the cooperation among neighbors.

The Concern about Housing Priority In response to questions in the survey regarding priority of new housing construction in order to accommodate the population influx, it was discovered that long-time and newly arrived residents agree about several housing issues within the context of their neighborhood and the city of Crete. Both groups of residents rate the quality and maintenance of housing in their neighborhood as somewhat good. They agreed that the availability of rental assistance for families in Crete was somewhat good, noting that an average of $40 \%$ of the respondents fell into this category. There was a spread of tenpercent difference in this consensus though, with $35.9 \%$ of newly arrived residents rating it as somewhat good, while $45.2 \%$ of long-time residents thought it was somewhat good.

The Investment for New Housing Development Long-time and newly arrived residents have some similar priorities when it comes to improving housing 
conditions in Crete. Building more modest income houses is important to $72 \%$ of newly arrived residents and $79.5 \%$ of long-time residents. Both groups of residents are equally divided when it comes to rating the importance of building more upscale homes, on average $42.5 \%$ of long-time and newly arrived residents rated this as less important, while an average of $32.3 \%$ of both groups rated this as important, so they agree but do not form a strong consensus. Building more rental apartments is important to an average of $75.3 \%$ of both groups however they vary in their degree of agreement. Over $80 \%$ of newly arrived residents view this as important while $69.6 \%$ of long-time residents view it as important.

\section{Differences in Perception}

The following are areas where there were significant differences between responses of long-time and newly arrived residents $(\mathrm{p}<.05)$.

Satisfaction of the Residents with their lives in Crete Long-time and newly arrived residents are generally satisfied with housing issues within the context of their neighborhood and the city of Crete; however, the degree of privacy they feel they have from others in their residence differs. More than $86 \%$ of long-time residents agree that they have enough privacy from others in their residence, while only $69 \%$ of newly arrived residents agree.

The Pressure on Public Municipal Services Do residents differ in their perception of pressure on public municipal services? Long-time and newly arrived residents only have one response to physical issues in which the two groups had a difference of perception. Newly arrived residents were typically satisfied with the traffic that goes through their neighborhood, while long-time residents were neutral on this topic.

The Stress of New Arrivals How did the new arrivals evaluate their new lives in Crete differently than long-time residents? Figure 8.5 illustrates the differences between the groups. 


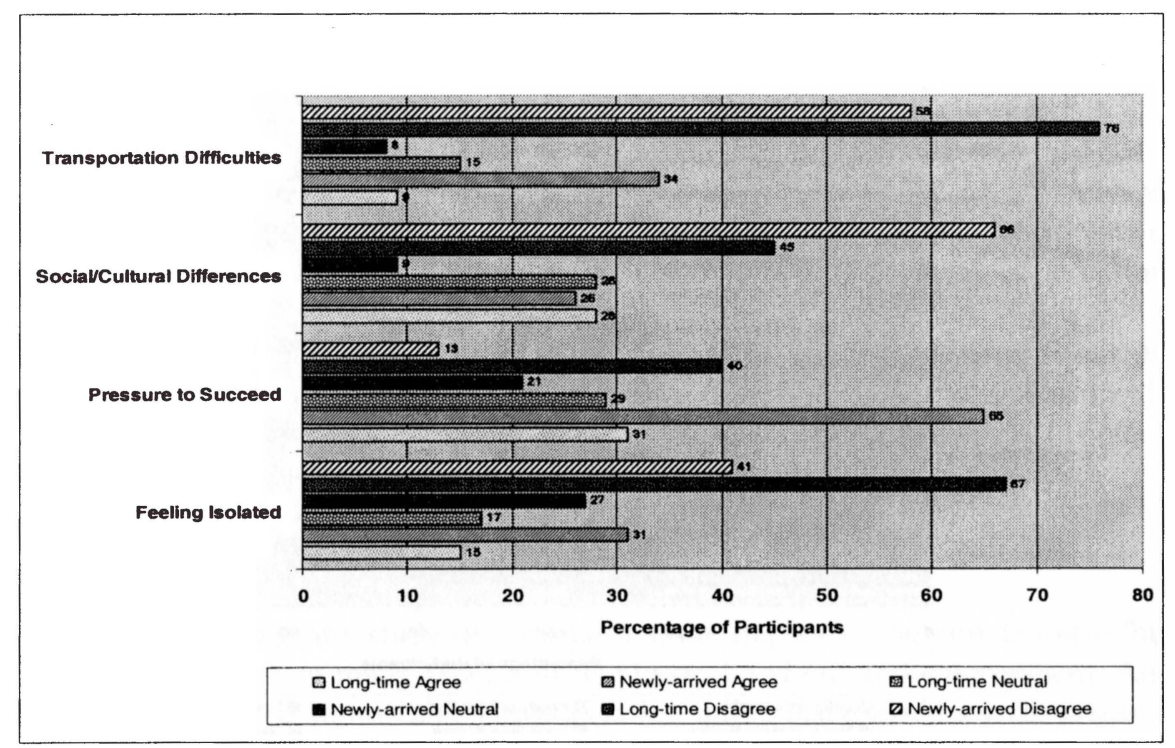

Figure 8.5 Perception similarities: stress related concerns

Long-time residents disagree by $67.4 \%$ that feeling isolated is a source of stress, while only $41.2 \%$ of newly arrived residents disagree. Even more significant, $31.4 \%$ of newly arrived residents agree feeling isolated is a source of stress for them. Long-time residents disagree that they feel pressure to do better, advance or succeed, and newly arrived residents do agree they feel pressure to do better. Social or cultural differences of people in the community are a source of stress for $66 \%$ of newly arrived residents, while $44.7 \%$ of long-time residents disagree that the social or cultural differences of people in the community are a source of stress. This is a large difference in their perception, however $27.7 \%$ of long-time residents remained neutral on this topic. Transportation is a source of stress for $34.0 \%$ of newly arrived residents, and $76.1 \%$ of long-time residents do not perceive transportation to be a source of stress. However, $58.0 \%$ of newly arrived residents disagreed that lack of transportation is a source of stress.

The Change in Neighborhoods: From Homogeneity to Heterogeneity The majority of both long-time and newly arrived residents feel that the population increase is an important factor that contributes to the current housing condition, as seen in Figure 8.6. 


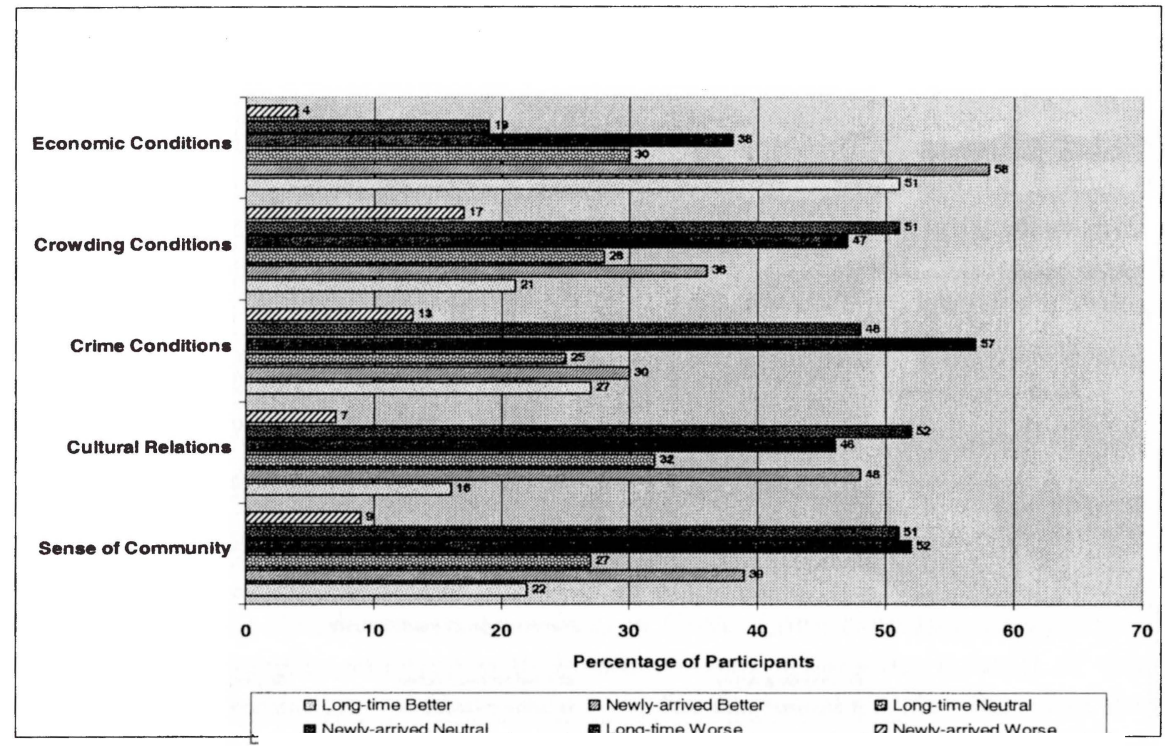

\section{Figure 8.6 Perception similarities: changes in Crete}

Where they differ is the level of their agreement, with $87.0 \%$ of long-time residents and $66.7 \%$ of newly arrived residents agreeing on the importance of this factor. Conversely, $25.5 \%$ of newly arrived residents were neutral in response to this, and $7.8 \%$ of newly arrived residents felt that this was less important, and no long-time residents viewed this factor as less important. An increase of industrial activity in the area is an important factor contributing to the current housing condition, with an amazing $91.5 \%$ of long-time residents perceiving this as important, and only $72.0 \%$ of the newly arrived residents agreeing.

Long-time and newly arrived residents have different perceptions concerning the change taking place in their neighborhoods. Long-time residents feel that the sense of community has gotten worse while newly arrived residents generally feel that it has gotten better. Long-time residents also feel that cultural relations have gotten worse, and newly arrived residents feel that they have gotten better. Longtime residents feel that crime conditions have gotten worse, and newly arrived residents feel that they have gotten better. Long-time residents feel that crowding conditions have gotten worse, and newly arrived residents feel that they have gotten better. The way the two groups view economic conditions also varies, with $57.7 \%$ of newly arrived residents, and $51.1 \%$ of long-time residents feeling they have improved, however $19.1 \%$ of long-time residents feel that it has gotten worse, as compared to $3.8 \%$ of newly arrived residents.

The Concern about Housing Priority In response to questions in the survey regarding priority of new housing construction in order to accommodate the population influx, it was discovered that long-time and newly arrived residents 
agreed on many points. It is interesting to view this agreement of perception in the context of their differing housing circumstances, with the majority of newly arrived residents renting and the majority of long-time residents as homeowners.

The Investment for New Housing Development Long-time and newly arrived residents have some differences in priorities when it comes to improving housing conditions in Crete. Building more housing for the elderly is important to $90.7 \%$ of long-time residents, while only $53.1 \%$ of newly arrived residents feel it is important.

Building more trailer parks is important to $38.8 \%$ of newly arrived residents, and is less important to $75.6 \%$ of long-time residents. However, $46.9 \%$ of newly arrived residents also feel it is less important.

\section{Discussion}

More than anything, the study discovered that the impact of the population influx on the city was felt in many aspects of its physical and cultural environment. And the impact is indeed significant. The population influx has exerted a great pressure on housing availability in the city, especially affordable housing. It has also changed the city's social and cultural landscape. It is evident from the survey results that long-time and newly arrived residents have both, similarities and differences, in their perceptions regarding Crete's quality of life.

Overall, Crete residents enjoy a good quality of life. In the majority of the survey results, residents expressed an appreciation for the good quality of life in Crete, and said that there is a 'sense of community' in Crete, and cooperation among neighbors. Residents said they could rely on friends for support in times of need, that Crete is beneficial for their family, and that they would recommend their immediate neighborhood to a friend. Residents feel safe from crime while in their residence, and there is a good level of police protection. They also feel that there is adequate off street parking, the level of street maintenance in the neighborhood, garbage collection, and the overall visual attractiveness of the neighborhood are good, as well as access to recreational services.

Additional efforts are needed to better meet the housing needs of Crete. Both long-time and newly arrived residents agree on factors contributing to the current housing conditions, as well as on the housing priorities of the community. Residents view the population, industrial activity, city housing policies, an aging population, lower paying jobs, economic conditions, and zoning as the major factors influencing current housing conditions. The residents agreed that housing priorities for the community include modest income housing, rental apartments, and elderly housing.

Long-time residents tend to feel conditions are worsening, while newly arrived residents tend to feel conditions are improving. It is important to notice the split in perception between the two groups of residents, and these observations can be found in the survey results. The major areas of concern include the 'sense of community', cultural relations, and crowding conditions. 
Newly arrived residents tend to feel higher levels of stress than long-time residents do. In general, both groups do not feel that life in Crete is very stressful, however the amount of stress perceived is different. Newly arrived residents feel higher amounts of stress than long-time residents due to income levels, communication difficulties, feelings of isolation, their job, racial discrimination, and lack of transportation.

\section{In Comparison to Schuyler}

The findings from this study of the impact of the population influx in Crete can be compared to the findings of a previous study of Schuyler, Nebraska. There are slightly different conditions in Schuyler than in Crete. In Schuyler, most of the newly arrived residents were Latino, and of those an overwhelming majority was of the Catholic faith. Whereas in Crete, there was a much more diverse group of newly arrived residents, both culturally and religiously. However, both cities have experienced a major population influx due to meat-packing plants in their community, and both studies utilized the same base survey and methods. Analyzing their results in parallel creates a larger base of information from which to learn, and some conclusions can be made.

Quality of Life Issues In Crete and Schuyler the long-time and newly arrived residents agree that they feel safe from being a victim of crime while in their residence, they are satisfied with the overall physical condition of their residence, and feel they have adequate off street parking. They also agree that there is sufficient privacy from neighbors.

Stress Issues In Crete and Schuyler the long-time and newly arrived residents agree that living in their community is beneficial for their family. They also agree that they can rely on their friends for support, and that they would recommend their immediate neighborhood to a friend. In Crete and Schuyler the newly arrived residents feel a greater pressure to do better, advance or succeed than the long-time residents. The long-time and newly arrived residents also disagreed regarding racial discrimination. None of the groups viewed racial discrimination the same way.

Housing and Homogeneity Issues In Crete and Schuyler the long-time and newly arrived residents agree that there is a good 'sense of community', and they feel there is cooperation among neighbors. They also all agree that the quality and maintenance of housing in their neighborhood is good, that their community should have priorities to build more modest income houses and rental apartments. In Crete the two groups agree that the availability for rental assistance is somewhat good, while in Schuyler the two groups said it was poor. In Crete and Schuyler the long-time residents felt that the crime conditions and the crowding conditions have gotten worse, while the newly arrived residents feel they have gotten better. 


\section{Conclusion}

At the end of each study the Quality of Life team offered various recommendations and possible actions for the community to take to improve the quality of community life. The Quality of Life team offered the following suggestions for the city of Crete. These suggestions were as follows: 1) Build on existing community initiatives that can make Crete's good quality of life even better; 2) Continue to explore ways to better provide for local housing needs in Crete; 3) Enhance community unity and cohesiveness by bridging the gap in perceptions between long-time and newly arrived residents; 4) Help make the transition easier and less stressful for newly arrived residents. It was suggested to the Crete community that they use their own expertise to come up with more recommendations and to pursue a plan of action that best fits the individual needs of the residents. What is down the line for this Quality of Life research? Currently the Quality of Life research team is pursuing the opportunity of carrying out a similar study in the community of Grand Island, Nebraska.

\section{References}

Austin, J. (1996). Migration in Nebraska Counties, 1980 to 2000. Business in Nebraska 52, no. 614 (October), 1-5.

Census 2000 data from www.census.gov

Gaber, S.L. and Cantarero, R. (1997). Hispanic Migrant Laborer Homelessness in Nebraska: Examining Agricultural Restructuring as One Path to Homelessness. MARS/Social Thought and Research 20(1-2), 55-72.

Gouveia, L. and Rousseau, M. (1995). Talk is Cheap: The Value of Language in the World Economy-Illustrations from the United States and Quebec. Sociological Inquiry 65(2), 156-180.

Gouveia, L. and Stull, D. (1997). Latino Immigrants, Meatpacking, and Rural Communities: A Case Study of Lexington, Nebraska Michigan State University: The Julian Samora Research Institute, unit of the Colleges of Social Sciences and Agriculture and Natural Resources. Research Report No. 26.

Potter, J., Cantarero, R., Yan, W., Larrick, S. and Ramírez, B. (1996). Residents' Perceptions of Housing and the Quality of Life in Schuyler, Nebraska. Lincoln: Final Report, University of Nebraska, College of Architecture.

Ramirez, B.E. (1998). The Influence of Micro and Macro Forces on Agriculture and Migration: Case Study of Hispanic Meatpackers in West Point, Thesis (M.C.R.P.), Lincoln: University of Nebraska.

University of Nebraska-Lincoln Cooperative Extension, IANR. 1995. Collaboration for Community Problem-Solving: Lexington, Nebraska 1993-1995. Lincoln: University of Nebraska - Lincoln Cooperative Extension, IANR. 